\title{
ULTRASOUND GUIDED INTERCOSTAL NERVE BLOCK FOR CHEST WALL PAIN AFTER THORACOTOMY FOR PULMONARY ECCHINOCOCCAL CYST EXCISION
}

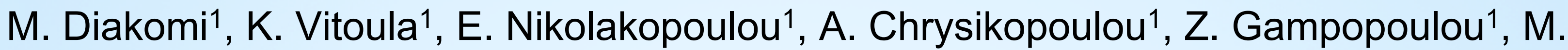
Konstantinidou ${ }^{1}$.

${ }^{1}$ General Hospital of Attica "KAT", Pain Evaluation and Therapy Center, Athens, Greece.

\section{Background and Aims:}

Treating chronic pain has been a challenging and demanding area for both the pain specialist and the patient. Pain following thoracic surgical procedures is a common finding that has been mainly attributed to intercostal nerve injury. There are several case reports referring to the efficacy of intercostal nerve blocks for postherpetic intercostal neuralgia, but there is insufficient data concerning their possible role for other chronic pain syndromes.

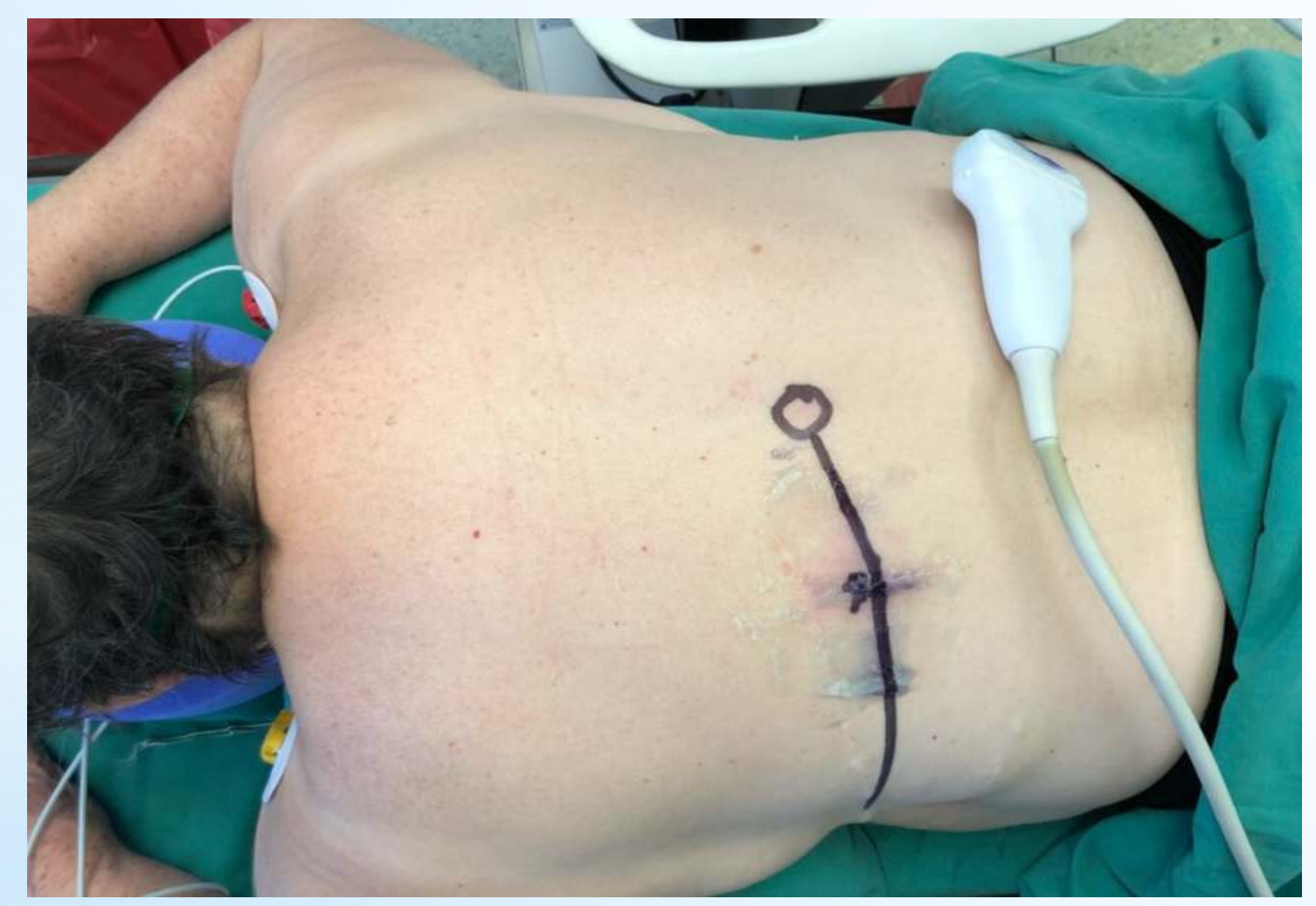

Methods:

A 69-year- old female underwent thoracotomy for pulmonary ecchinococcal cyst excision 34 years ago. She had been suffering recurrent pulmonary infections ever since. The patient presented in our Pain Department complaining for continuing stabbing thoracic pain at the vicinity of surgical incision, starting approximately 2 years ago. The clinical examination revealed an obvious trigger point in the posterior surface of the left hemi-thorax, at the $6^{\text {th }}$ thoracic level.
After explaining the procedure to the patient and having obtained informed consent, we performed US-guided intercostal nerve block at the location of the trigger point at the $6^{\text {th }}$ thoracic level $(1 \mathrm{ml}$ ropivacaine $2 \% / 8 \mathrm{mg}$ dexamethasone).

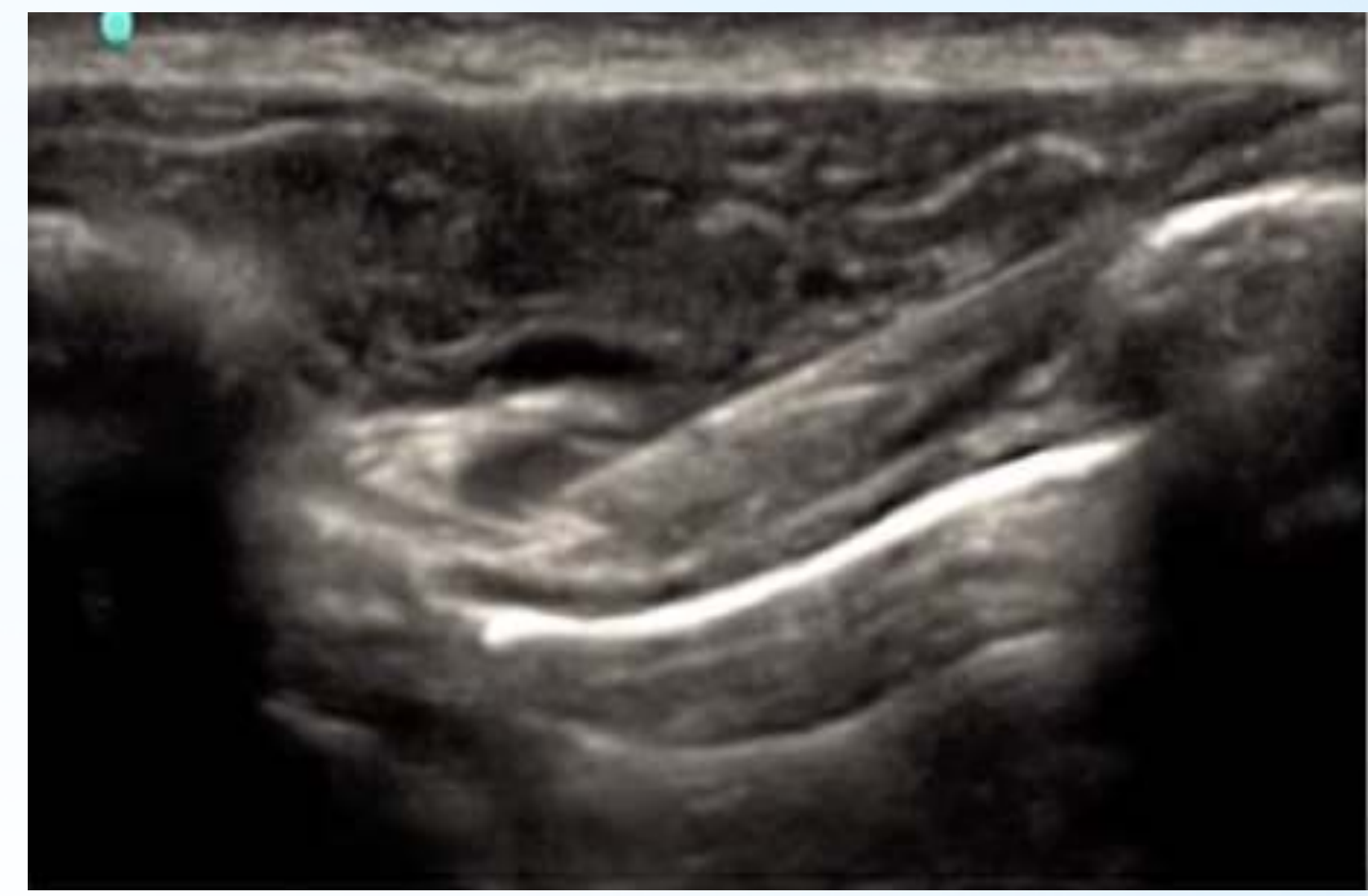

Results

No adverse effect was reported after our intervention. The patient is on a weekly phone follow -up for already 20 days reporting reduced pain scores and duration, improving patient's respiration and quality of life.

\section{Conclusions:}

Our case provides evidence confirming the efficacy and safety of intercostal nerve block for treating chronic chest wall pain. US-guidance should be preferred as intercostal nerve injections are more accurate when compared to landmark technique.

Bibliography

1. Doi K, Nikai T, Sakura S, Saito Y. Intercostal nerve block with $5 \%$ tetracaine for chronic pain syndromes. J Clin Anesth. 2002 Feb; 14(1): 39-41.

2. Curaloto M, Eichenberger U. Ultrasound -guided blocks for the treatment of chronic pain. Tech Reg Anesth Pain Manag. 2007; 11:95-102 